\title{
Apoptosis as a Target for Gene Therapy in Rheumatoid Arthritis
}

\section{Gabriel Adrián Rabinovich}

Laboratorio de Inmunogenética, Hospital de Clínicas “José de San Martín”, Facultad de Medicina, Universidad de Buenos Aires, Córdoba 2351, 3er Piso, 1120 Buenos Aires, Argentina

Rheumatoid arthritis $(R A)$ is characterized by chronic inflammation of the synovial joints resulting from hyperplasia of synovial fibroblasts and infiltration of lymphocytes, macrophages and plasma cells, all of which manifest signs of activation. All these cells proliferate abnormally, invade bone and cartilage, produce an elevated amount of pro-inflammatory cytokines, metalloproteinases and trigger osteoclast formation and activation. Some of the pathophysiological consequences of the disease may be explained by the inadequate apoptosis, which may promote the survival of autoreactive $T$ cells, macrophages or synovial fibroblasts. Although $R A$ does not result from single genetic mutations, elucidation of the molecular mechanisms implicated in joint destruction has revealed novel targets for gene therapy. Gene transfer strategies include inhibition of pro-inflammatory cytokines, blockade of cartilage-degrading metalloproteinases, inhibition of synovial cell activation and manipulation of the Th1-Th2 cytokine balance. Recent findings have iluminated the idea that induction of apoptosis in the rheumatoid joint can be also used to gain therapeutic advantage in the disease. In the present review we will discuss different strategies used for gene transfer in RA and chronic inflammation. Particularly, we will highlight the importance of programmed cell death as a novel target for gene therapy using endogenous biological mediators, such as galectin-1, a $\beta$-galactoside-binding protein that induces apoptosis of activated $T$ cells and immature thymocytes.

Key words: apoptosis - gene therapy - rheumatoid arthritis - galectin-1

IMMUNOPATHOGENIC MECHANISMS OF RHEU-
MATOID ARTHRITIS: AN OVERVIEW

Rheumatoid arthritis (RA) is a common (about $1 \%$ prevalence) chronic autoimmune inflammation of the synovial joints resulting from hyperplasia of synovial fibroblasts and infiltration of lymphocytes, macrophages, and plasma cells, all of which manifest signs of activation (Feldmann et al. 1996). Despite a lack of knowledge about its ethiology, there has been recent significant progress in understanding its pathogenic mechanisms. The disease is mainly characterized by (a) chronic inflammation, (b) an exacerbated immune response, (c) synovial hyperplasia and (d) dysregulated apoptosis. Rheumatoid synovial cells are phenotypically transformed to proliferate abnormally. They invade bone and cartilage and induce tissue degradation by producing an elevated amount of

\footnotetext{
The results presented in the last part of this review were supported by grants from Fundación Antorchas (Argentina) and British Council.

Fax: +54-11-4508-3780.

E-mail: gabyrabi@ ciudad.com.ar

Received 7 August 2000

Accepted 4 September 2000
}

pro-inflammatory cytokines and metalloproteinases and by inducing osteoclast formation and activation . The activated phenotype of synovial cells is marked by an upregulation of proto-oncogenes, which are involved in important cellular events such as intracellular signaling and gene transcription (Takayanagi et al. 1999).

Animal models of RA, such as collagen-induced arthritis (CIA) in DBA/1 strain of mice, adjuvant-induced arthritis in Lewis rats and antigeninduced arthritis in rabbits have been essential in understanding the possible pathogenic mechanisms of this disease (Courtenay et al.1980, Chernajovsky et al. 1995, Evans \& Robbins 1996). They have been also served as basic models for the development of therapeutic strategies.

An ideal therapy in RA should ameliorate disease, prevent joint destruction, maintain function, prevent the development of extra-articular complications such as vasculitis, serositis, lung fibrosis and prevent premature death. However, there is no current effective therapy capable of preventing disease progression and joint damage. Longterm expression of biological agents can have deleterious effects such as altering the immune response to infectious pathogens inducing a transient immunodeficient state. To overcome existing problems associated with drug delivery to articular tis- 
sues, several strategies have been explored for the application of gene therapy in the treatment of RA and other autoimmune disease (Chernajovsky et al. 1998). The present review will be focused on novel strategies used for gene therapy in RA based on the immunopathogenic mechanisms of the disease. For this purpose, a brief introduction will be first presented with the basic principles of gene therapy, its requirements and the most relevant delivery systems.

\section{GENE THERAPY: BASIC PRINCIPLES, REQUIRE- MENTS AND DELIVERY SYSTEMS}

Gene therapy offers an unorthodox treatment paradigm for curing human disease (Weatherall 1995). This new type of pharmacology that has revolutionized the "classical" medicine, can be defined as the "transfer of genetic material to somatic target cells with resulting therapeutic benefit to the individual" (Kerr \& Mulé 1994, Weatherall 1995). Rather than altering the disease phenotype using agents which interact with gene products, gene therapy can theoretically modify specific genes resulting in disease amelioration following a single administration. Initially, gene therapy was envisioned for the treatment of monogenic disorders such as cystic fibrosis or severe combined immunodeficiency, but is currently being studied in a wide range of diseases including cancer, neurodegenerative disorders, human immunodeficiency virus infection, autoimmunity and other acquired diseases.

In general, the requirements for gene therapy, while easily stated, have been extremely difficult to fulfill. First, it is necessary to isolate a particular gene together with its regulatory sequences. Second, it must be possible to obtain sufficient number of the cells into which the gene is to be inserted and find an effective way of returning them to the patient. Third, there must be an efficient mechanism for inserting the gene into target cells. And, finally, the inserted gene must produce sufficient amounts of its product over a reasonable length of time, and the procedure must not have any deleterious effects (Weatherall 1995, Chernajovsky et al. 1998). Therefore, gene therapy protocols involve the transfer of genes to cells, with the goal that expression of the transferred gene will ameliorate disease.

The key to success for any gene therapy strategy is having a vector able to serve as a safe and efficient gene delivery vehicle. Viruses have drawn the most attention as potential vectors. They are attractive because evolution has designed them specifically to enter cells and express their genes there. Further, it is possible to substitute one or more therapeutic genes for genes involved in viral replication and virulence. Because they integrate DNA into the genome much recent research in gene transfer has focused on retroviral vectors (Weatherall 1995, Beutler 1999), which are retroviruses from which many of the viral genes have been removed so that no viral proteins can be made in the cells they infect. The main advantage of retroviral vectors is the high efficiency of gene transfer into replicating cells. Among the drawbacks of retroviral gene transfer, it is difficult to insert large pieces of DNA into these vectors and most retroviruses are unable to infect non-dividing cells. Furthermore, integration is random and there is a danger of unwanted sideeffects such as insertional mutagenesis. Other viral transfer systems have been explored such as adenovirus, adeno-associated virus (AAV) and herpes simplex virus (HSV). Adenoviral vectors have the advantage that they can carry larger segments of DNA and infect non-replicating cells. Moreover, AAV are satelite viruses of other human viruses and require co-infection for their replication. This kind of vectors such as AAV have been designed to produce a gene therapy vehicle with site-specific integration and the ability to infect multiple cell types (Beutler 1999).

Non-viral techniques for gene therapy include the use of plasmid and liposomes. Liposomes offer several advantages in delivering genes to cells such as safety and the possibility to target specific cells or tissues. However, current limitations regarding in vivo application of liposomes as vectors for gene therapy include low transfection efficiencies and transient gene expression. The ability to overcome these problems should greatly facilitate their application to a wide variety of gene delivery mechanisms (Weatherall 1995).

RHEUMATOID ARTHRITIS: A CANDIDATE DISEASE FOR GENE THERAPY

Although RA is a complex polygenic and multifactorial disorder, elucidation of the cellular and molecular mechanisms implicated in the pathogenesis of joint destruction and immune cell activation have revealed novel targets for gene therapy of this disease (Jorgensen \& Gay 1998). In RA the therapeutic gene to be introduced will interfere with the disease process or modify the development of the disease by introduction of biological response modifiers such as cytokine antagonists, protease inhibitors or antisense oligonucleotides (Chernajovsky et al. 1995b). As stated, the advantage of gene therapy regarding protein therapy is that local expression of antagonists or immunomodulators, reduce the incidence of systemic complications.

Gene transfer strategies for inhibiting joint destruction in RA are summarized in the Table and 
include: (a) inhibition of pro-inflammatory cytokines such as TNF- $\alpha$, IL-1 and IL-15, (b) bias of the cytokine profile from a Th-1 towards a Th2-polarized immune reaction (using IL-4, IL-10, IL-13) and (c) deviation towards an immunosuppresive state characteristic of a Th-3 response (IL-10 and TGF- $\beta$ ). Novel attractive strategies propose the blockade of synovial cell activation (by inhibiting specific signal transduction pathways) and inhibition of matrix-degrading enzymes. Moreover, recent experimental evidence have illuminated the idea that induction of apoptosis of rheumatoid synovium can be used to gain therapeutic advantage (Vaishnaw et al. 1997, Jorgensen \& Gay 1998, Chernajovsky et al. 1999). Therapeutic genes may be introduced locally into diseased joints (local gene delivery) or at extra-articular locations where the gene products become systemically available (systemic gene delivery). Moreover, gene therapy in RA can be carried out in vivo by intraarticular injection of the recombinant vector or $e x$ vivo. The advantage of ex vivo procedures is that autologous synoviocytes removed from RA patients during arthroscopy are transduced in the laboratory and selected for expression and safety before being reintroduced into the joint (Jorgensen $\&$ Gay 1998). Possible target cells for gene therapy in RA include autologous synoviocytes, pathogenic lymphocytes, keratinocytes, hepatocytes, embryonic fibroblasts and muscle cells.

\section{GENE TRANSFER IN RA BY INHIBITING PRO-IN- FLAMMATORY CYTOKINES}

The immunopathology of RA is associated with the production of pro-inflammatory cytokines, such as IL-15, TNF- $\alpha$, IL-1 and IL-6 (Feldmann et al. 1996). It is now known that release of these cytokines by the inflamed synovium in RA leads directly to the destruction of the adjacent bone and cartilage through the induction of metalloproteinase (MMP) production in synovial fibroblasts. To date, IL- 1 and TNF- $\alpha$ are considered the most powerful "destructive" cytokines with regards to MMP induction and consequent proteolytic activation and tissue destruction in chronic synovitis (Dayer 1997). The homeostasis of cytokine biology is controlled by cytokines with opposite functions and by natural antagonists. The first evidence of the concept of true receptor antagonists came from studying the biology of IL-1, when binding experiments revealed a competitive mechanism at the receptor level. IL-1 can be blocked through competitive inhibition by its natural antagonist IL-1Ra (IL-1 receptor antagonist), which competes for binding of IL-1 or by its soluble receptors (I and II), which function as decoys of the pro-inflammatory cytokine (Chernajovsky et al. 1995). Par- ticularly, IL-1Ra competitively inhibits the biologic activities of IL-1 by occupying the type I IL-1 receptor without eliciting a signal transduction response. Several experimental evidence were provided, showing that gene transfer of IL-1 antagonists could be therapeutic in models of antigeninduced arthritis in rabbits and CIA (Evans \& Robbins 1996, Otani et al. 1996, Makarov et al. 1996). All different experimental strategies using IL-1 inhibitors revealed a marked, although not complete, anti-inflammatory and condroprotective effects. Recently, Oligino et al. (1999) have demonstrated the anti-inflammatory properties of the intra-articular delivery of a second generation HSV vector containing the IL-1Ra gene.

On the other hand, there are two types of soluble TNF receptors (TNF-sR) that mediate different biological activities: type I TNF-sRI (p55) and type II TNF-sR (p75). These soluble inhibitors of TNF- $\alpha$ constitute a mechanism that counters the deleterious effect of TNF- $\alpha$. In fact, an inverse correlation has been observed between the level of TNF-sR and the mortality of patients (Dayer 1997). In vitro studies using dissociated synovial membrane cells from RA patients have generated the hypothesis that TNF- $\alpha$ plays a pivotal role in joint inflammation through the induction of other pro-inflammatory cytokine such as IL-1, IL-6, GMCSF and IL-8 (Feldmann et al. 1996). Consistently, DBA/1 mice expressing the human TNF- $\alpha$ transgene developed a severe and erosive arthritis (Butler et al. 1997). Anti-TNF therapy has been successfully used in diverse animal models of RA (Williams et al. 1992, Chernajovsky et al. 1998, Quatrocchi et al. 1999). Chernajovsky and colleagues (1995a) have used a retroviral vector containing a soluble monomeric $\mathrm{p} 75 \mathrm{TNF}$ receptor to infect arthritogenic splenocytes from DBA/1 mice and inhibited the transfer of CIA to severe combined immunodeficient (SCID) mice. Moreover they were able to prevent collagen-induced arhtritis by gene delivery of soluble p75 TNF receptor (Mageed et al. 1998). The important role of TNF- $\alpha$ in RA has been finally established not only in animal models but also in clinical trials where antiTNF- $\alpha$ mAbs administered to patients with longstanding active RA were found to be benefical (Elliot et al. 1994). Another approach to TNF inhibition could also involve ribozymes that catalitycally inhibit TNF mRNA (Chernajovsky et al. 1998).

Finally, recent studies showing that IL- 15 could act upstream of the cytokine cascade in RA and induce TNF- $\alpha$ production, have envisaged the development of gene therapeutic strategies using specific inhibitors of this novel cytokine (McIness et al. 1997). In this context, Ruchatz et al. (1998) have 
recently reported that administration of a soluble IL-15 receptor $\alpha$-chain was able to profoundly suppress the development of CIA. Thus, a sustained increase of sufficient magnitude in the levels of pro-inflammatory cytokine antagonists provided by local gene delivery using retroviral or adenoviral vectors, should inhibit the arthritogenic process. However, targeting only a single molecule is unlikely to be sufficient for inhibiting the destruction of cartilage and bone in RA (Jorgensen \& Gay 1998).

TARGETING INFLAMMATION AND AUTOIMMUNITY BY SKEWING THE BALANCE TOWARDS A TH2-POLARIZED IMMUNE RESPONSE

The cytokine profile in RA joint is dominated by macrophage and fibroblast products, although small quantities of $\mathrm{T}$ cell cytokines have been identified. Of these cytokines, the majority are derived from cells exhibiting the Th- 1 cytokine (IL-12, IL2 , IFN- $\gamma$ ). Th- 2 cytokines including IL-4, IL-5, IL10 and IL-13 suppress Th-1 function and pro-inflammatory cytokine production by a "cross-talk" mechanism. The Th- $1 /$ Th- 2 cytokine imbalance has been suggested as a mechanism to perpetuate joint disease in RA, since Th- 2 cytokines remain insufficient to counteract the level of Th-1 and pro-inflammatory cytokines (Chernajovsky et al. 1995b, Mauri et al. 1996). Therefore, many gene transfer strategies include the introduction of Th2-derived cytokines such as IL-4 (Lubberts et al. 1999, Boyle et al. 1999), IL-10 (Apparailly et al. 1998) and IL13 (Bessis et al. 1996).

Several results support the concept that overexpression of the immunosuppressive cytokine TGF- $\beta$ might be a feasible approach for the inhibition of the inflammatory response and cartilage destruction in RA. This cytokine is an excellent candidate for systemic gene therapy, since it is produced and transfected as a latent ("silent") cytokine and is only activated at sites of inflammation by enzymatic degradation or $\mathrm{pH}$ modifications. Chernajovsky and colleagues (1997) have engineered arthritogenic lymphocytes to express TGF$\beta 1$ from a retroviral vector, showing that amelioration of established arthritis can be achieved by gene therapy using this cytokine.

\section{BLOCKING TISSUE DESTRUCTION BY INHIBIT- ING MATRIX-DEGRADING ENZYMES}

It has been demonstrated that the destruction of the extracellular matrix in RA is mediated by matrix metalloproteases (MMP) in the extracellular synovial environment (Dayer 1997). The effect of these enzymes is downregulated by natural inhibitors called TIMPs (tisssue inhibitors of MMPs). The main source of MMPs are synovial fibroblasts and cells of the monocyte-macrophage lineage. While IL-1, TNF- $\alpha$ and prolonged T cell stimulation have been shown to promote MMP production, TGF- $\beta$, IL-10 and IL-13 induce TIMP1 production, generating an homeostasis at the proteolytic level of joint destruction. In this context, another attractive target for gene therapy could be the inhibition of matrix-degrading enzymes using oligonucleotide antisense or ribozymes that cleave MMPs mRNA (Jorgensen \& Gay 1998). In this context, overexpression of TIMPs could also be relevant in the inhibition of bone and cartilage destruction in RA.

GENE THERAPY IN RA BY BLOCKING ACTIVATION OF SPECIFIC TRANSCRIPTION FACTORS: A ROLE FOR NF-kB

Nuclear factor kappa B (NF-kB) is a heterodimeric transcription factor that is a critical element in the regulation of many genes involved in the regulation of the immune response (Vaishnaw et al. 1997). It has been shown that TNF- $\alpha$ signals predominantly through the NF-kB pathway, promoting the expression of adhesion molecules (ICAM-1, VCAM-1) and recruiting additional cytokines (IL-1, IL-6, GM-CSF) in the inflamed joint. Signaling through NF-kB has been shown to stimulate the pro-inflammatory cascade and promote tissue destruction (Fujisawa et al. 1996). Dissociation of the transcription factor NF-kB from its natural inhibitor Ik-B has been reported to play a pivotal role in the production of inflammatory cytokines and chemokines by inducing a coordinated transactivation of genes such as TNF- $\alpha$, IL-1, IL-8, ICAM-1 and inducible nitric oxide sintase (iNOS). Recently, Tomita et al. (1999) have demonstrated that administration of a NF-kB decoy oligodeoxynucleotide into arthritic joints led to a marked amelioration of the disease and suppressed the production of pro-inflammatory cytokines, providing a useful approach for the treatment of RA.

INHIBITION OF THE INFLAMMATORY RESPONSE BY DISRUPTING SPECIFIC INTRACELLULAR SIGNALING PATHWAYS AND INHIBITING CELL CYCLE PROGRESSION

Recent studies have been designed to inhibit different signaling mechanisms in the activation of synovial fibroblasts (Table). These include interference with the Ras-Raf MAPK pathway (Jorgensen \& Gay 1998) and inhibition of the Src tyrosine kinase (Takayanagi et al. 1999). These have been implicated in several biological functions, including mitogenic response to growth factors and cytokines, activation of lymphocytes and osteoclastic bone resorption. Therefore, inhibiting Src activity has been propose as an excellent can- 
didate for gene therapy to prevent joint inflammation and destruction in RA. The kinase activity of $\mathrm{Src}$ is negatively regulated by phosphorilation with another cytoplasmic tyrosine kinase named Csk (Cterminal Src kinase). Adenovirus-mediated overexpression of Csk tyrosine kinase dramatically reduced the proliferation rate and inflammatory activity in the joint by suppressing Src activity and almost completely repressed the bone-resorbing activity of osteoclasts (Takayanagi et al. 1999). Recently, Taniguchi et al. (1999) have also shown that cyclin-dependent kinase inhibitors, such as p16 INK4a gene can be used by gene transfer to suppress synovial cell proliferation.

GENE TRANSFER IN RA BY PROMOTING APOPTOSIS OF SYNOVIOCYTES AND IMMUNE CELLS

To conclude this review, we will focus our attention on the importance of dysregulated cell death in the pathogenic mechanisms of autoimmune inflammation in RA and the possibility to exploit this situation for gene therapy in RA.

\section{TABLE}

Candidate targets for gene therapy in rheumatoid arthritis

\footnotetext{
Inhibition of synoviocyte activation

Inhibition of pro-inflammatory cytokines

Inhibition of specific transcription factors (NF-kB)

Inhibition of osteoclastogenesis and cartilage degradation

Blockade of matrix-degrading enzymes

Bias towards a Th2/Th3-polarized immune response Inhibition of cell-cycle progression

Inhibition of specific signal transduction pathways

Induction of apoptosis of synoviocytes and

inflammatory cells
}

\section{DISREGULATED APOPTOSIS TRIGGERS AUTOIM- MUNITY}

A dynamic balance in the quantity and activation state of the cells participating in immune responses is essential for achieving appropriate proliferative and effector responses to antigens while avoiding autoimmunity (Lenardo 1997). Lymphocytes with receptors capable of recognizing self antigens are generated constantly, yet normal individuals maintain a state of unresponsiveness to their own antigens, called self-tolerance. Apoptosis acts to preserve central and peripheral $\mathrm{T}$ cell homeostasis regulating the tempo and duration of immune responses in vivo. This has been best defined for lymphocytes for which removal of $\mathrm{T}$ or $\mathrm{B}$ cells by antigen receptor engagement or the loss of trophic stimuli, leads to apoptosis during and after peripheral immune response, thereby allowing feedback regulation. Antigen-provoked death of lymphocytes is mediated by Fas (CD95/ APO1), tumor necrosis factor (TNF) and related molecules. Other death ligands such as TRAIL and its corresponding death receptors DR4 and DR5 are expressed in immune cells, but their physiological functions are now well understood (Vaishnaw et al. 1997).

Studies of mouse strains with genetic predisposition to autoimmune disease suggest that in addition to regulating responses to exogenous antigens, apoptosis of mature T cells maintains tolerance to self antigens (Singer et al. 1994). Mice homozigous for the lpr or gld mutations manifest hypergammaglobulinemia, autoantibody production, arthritis, vasculitis and accumulation of nonmalignant TCR $\alpha \beta \mathrm{CD}^{-}{ }^{-} \mathrm{CD} 8^{-} \mathrm{T}$ lymphocytes in their secondary lymphoid organs. Genetic cloning and mapping studies revealed that $l p r$ was a recessive mutation in Fas while gld was a mutation in the gene for Fas ligand (Fas L). Homozygosity for either $l p r$ or gld causes defective $\mathrm{T}$ cell receptor (TCR)-induce death of mature T cells. While inbred mouse strains bearing lpr or gld mutations provided convincing evidence that failure of mature $\mathrm{T}$ cell deletion may breach peripheral tolerance, such evidence has been lacking in humans. However, Fisher et al. (1995) have identified the presence of the autoimmune lymphoproliferative syndrome (ALPS) as an inhereted disease of unbalanced lymphocyte homeostasis and defective apoptosis. In this syndrome defective apoptosis permits the accumulation of lymphocytes, including a usually rare population of double negative $\mathrm{T}$ cells and the occurrence of antibody-mediated autoimmune disorders.

\section{APOPTOSIS: A NOVEL TARGET FOR GENE THERAPY IN RA?}

Two major pathogenic processes have been clearly identified in the development of RA, the first involving abnormal synoviocyte proliferation, and the second dependent on T cells and macrophage activation (Vaishnaw et al. 1997). Hence, RA could also be explained as a result of cell accumulation and soluble mediators that affect the lifedeath decisions, protecting synovial and immune cells from apoptosis. Accordingly, it has been shown that IL-1 $\beta$ inhibits susceptibility to apoptosis, an effect associated with increased expression of the Bcl-2 family of proteins (Vaishnaw et al. 1997). Moreover, TNF- $\alpha$, which acts as a potent pro-inflammatory molecule in RA signals predominantly through the NF-kB pathway recruiting additional cytokines. Signaling through this transcription factor would also be expected to in- 
hibit apoptosis (Fujisawa et al. 1996). Finally, mutations of the p53 protein have been detected in the inflamed joint (Vaishnaw et al. 1997).

Effective treatment of arthritis will require the elimination of proliferating synoviocytes and arthritogenic lymphocytes that initiate and perpetuate joint inflammation. Hence, attempts to induce apoptosis either in rheumatoid synovium or activated immune cells will be clearly benefical for the treatment of joint disease. In this context, Okamoto et al. (1998) investigated the apoptotic effects of Fas ligand-transfected cells on proliferating human rheumatoid synovium engrafted in severe combined immunodeficient (SCID) mice. Moreover, Zhang et al. (1997) reported the amelioration of CIA after adenoviral-mediated gene transfer of Fas $\mathrm{L}$ to arthritic joints. Fas-associated death domain protein (FADD) has been shown to bind to the intracellular death domain of Fas and promote signaling pathways of Fas-mediated apoptosis. Kobayashi et al. (2000) have recently investigated the effects of FADD gene transfer into cells of the rheumatoid synovium using adenoviral vectors, which have been reported to be the most efficient vectors for gene transfer into synovial cells. Transduction of FADD gene enhanced apoptosis of proliferating human rheumatoid synovium engrafted in SCID mice. Moreover, very recent studies revealed by gene therapy that TRAIL (TNF-related apoptosis inducing ligand) is a potent inhibitor of autoimmune inflammation in arthritis by blocking cell cycle progression (Song et al. 2000). Finally, an attractive strategy to use in RA would be the "suicide" gene therapy already used for brain tumors. This strategy involves insertion into the rheumatoid synovium of the gene encoding the thymidine kinase (tk) enzyme from HSV using retroviral vectors. In cells infected with HSV vector, the enzyme will convert the otherwise non-toxic drug ganciclovir into a toxic metabolite that acts as a potent cell killer. Elucidation of the specific mediators and biochemical pathways that regulate cell death will be critical for therapeutic manipulation of RA and other autoimmune and inflammatory diseases.

\section{GALECTINS: A LINK BETWEEN APOPTOSIS AND AUTOIMMUNITY}

Galectin-1 (Gal-1) is a member of a growing family of animal $\beta$-galactoside-binding proteins, which are highly conserved throughout animal evolution and share sequence similarities in the carbohydrate recognition domain (CRD) (Rabinovich 1999a,e). Its presence has been localized within the central and peripheral immune compartment in thymic epithelial cells (Baum et al. 1995), activated T cells (Blaser et al. 1998) and activated macrophages (Rabinovich et al. 1996, 1998). Recent observations suggest that Gal- 1 could play an important role in generating and maintaining central and peripheral immune tolerance (Rabinovich et al. 1999e). This homodimeric protein has been shown to suppress $\mathrm{T}$ cell proliferation (Rabinovich et al. 1997) and induce apoptosis of activated mature T cells (Perillo et al. 1995, Rabinovich et al. 1998) and particular subsets of immature cortical thymocytes through modulation of $\mathrm{T}$ cell receptor (TCR)-mediated responses (Perillo et al. 1997, Vespa et al. 1999). The apoptotic effect of Gal-1 depended upon the activation state of T cells and was mediated by engagement of CD43 and CD45, particularly the poly-lactosamine-enriched CD45RO splicing product (Perillo et al. 1997). We have recently shown that Gal-1-induced apoptosis is preceded by an early upregulation of the $c$-Jun proto-oncogene and further activation of the AP-1 transcription factor and is accompanied by a downregulation of Bcl-2 (Rabinovich et al. 2000a). Therefore, this protein has been shown to downmodulate exacerbated immune responses and inflammatory processes. In collaboration with the laboratory of Dr O Lider from the Weizmann Institute of Science (Rehovot), we have demonstrated that Gal-1 is able to inhibit T cell adhesion to ECM glycoproteins and block the production of pro-inflammatory cytokines, which could be highly significant for immune intervention in RA (Rabinovich et al. 1999b).

All these observations prompted us to investigate in vivo the immunoregulatory properties of Gal-1 using the CIA model in DBA/1 mice. We generated the hypothesis that Gal-1-induced apoptosis could provide for an ideal mechanism using a naturally occurring protein to terminate the autoimmune T cell attack, preventing the expansion of dominant autoaggressive clones and inhibiting the inflammatory response. Hence, a collaborative project was performed with the laboratory of Dr Y Chernajovsky from the Kennedy Institute of Rheumatology (London) to test by gene therapy the immunosuppressive properties of this protein. A single injection of syngeneic DBA/1 fibroblasts engineered to secrete Gal-1 at the day of disease onset was able to abrogate clinical and histopathological manifestations of arthritis, inducing a bias from a Th-1 to a Th-2-polarized immune reaction (Rabinovich et al. 1999c). This effect was also manifested by a reduced level of anti-collagen typeII specific antibodies. The molecular mechanism of the therapeutic effect was confirmed in vivo since lymph node cells from mice engaged in the gene therapy protocol increased their susceptibility to antigen-induced apoptosis (Rabinovich et al. 1999c). Moreover, Gal-1-expressing fibroblasts 
revealed an inhibitory effect in antigen-dependent IL-2 production to a collagen type II-specific T cell hybridoma clone. This study provided a strong correlation between the apoptotic properties of Gal1 in vitro and its therapeutic potential in vivo. Our results have been recently reproduced by Santucci et al. (2000) who reported that Gal-1 suppressed the inflammatory response in a model of autoimmune hepatitis in mice. We have also demonstrated using an experimental model of acute inflammation, that in addition to the pro-apoptotic activity, Gal-1 also exhibits intrinsic anti-inflammatory properties, which are independent of its carbohydrate-binding activity and affects both soluble and cellular mediators of the inflammatory cascade (Rabinovich et al. 2000b).

\section{FUTURE PERSPECTIVES}

RA is a chronic inflammatory autoimmune disease in which several promising strategies of gene transfer have been proposed. Effective treatment has been achieved in animal models using cytokine antagonists, Th- 2 cytokines, MMP inhibitors, ribozymes, decoys and pro-apoptotic mediators. Despite the advantages of gene therapy, the majority of the work to date refers to the constitutive expression of therapeutic genes. As with Gal-1, long-term expression of biological agents can have secondary effects such as altering the immune response to infectious pathogens (Chernajovsky et al. 1997). To prevent such an outcome transcriptionally regulated gene expression is necessary. The use of the tetracycline-inducible operon, which is activated by tetracycline derivatives, is a possible solution to this problem, inducing the expression of the therapeutic gene only when necessary. As with so many other unexplored areas of science, researchers are just beginning to learn about its potential and limitations. Conclusive data on the application of gene therapy strategies for the treatment of human RA can be obtained by clinical testing. The design of new generation vectors, novel methods to introduce therapeutic genes and better selection of target cells will provide new insights into the clinical applications of gene therapy in RA.

\section{ACKNOWLEDGEMENTS}

To Dr Y Chernajovsky, who helped me to learn the $\mathrm{ABC}$ of gene therapy. To Dr L Fainboim, Dr C Riera and Dr O Lider for continuous support and encouragement. To Ms L Molinero, $\mathrm{N}$ Rubinstein and Mr F Zaldivar for kind assistance.

\section{REFERENCES}

Apparailly F, Verwaerde C, Jackquest C, Auriault C, Sany J, Jorgensen C 1998. Adenovirus-mediated transfer of viral IL-10 gene inhibits murine collagen- induced arthritis. J Immunol 160: 5213-5220.

Baum LG, Pang M, Perillo NL, Wu T, Delegaene A, Uittenbogaart CH, Fukuda M, Seihamer JJ 1995. Human thymic epithelial cells express an endogenous lectin, galectin-1, which binds to core 2 O-glycans on thymocytes and T lymphoblastoid cells. J Exp Med 181: 877-887.

Bessis N, Boissier MC, Ferrara P, Blankenstein T, Fradelizi D, Fournier C 1996. Attenuation of collagen-induced arthritis in mice by treatment with vector cells engineered to secrete interleukin-13. Eur J Immunol 26: 2399-2403.

Beutler E 1999. Gene therapy. Biol Bone Marrow Transplant 5: 273-276.

Blaser C, Kaufmann M, Muller C, Zimmerman C, Wells V, Mallucci L, Pircher H 1998. Beta-galactosidebinding protein secreted by activated $\mathrm{T}$ cells inhibits antigen-induced proliferation of T cells. Eur $J$ Immunol 28: 2311-2319.

Boyle DL, Nguyen KHY, Zhuang S, Shi Y, McCormack JE, Chada S, Firestein GS 1999. Intra-articular IL-4 gene therapy in arthritis: anti-inflammatory effect and enhanced Th2 activity. Gene Ther 6: 1911-1918.

Butler DM, Malfait AM, Mason LJ, Warden PJ, Kollias G, Maini RN, Feldmann M, Brennan F 1997. DBA/ 1 mice expressing human TNF- $\alpha$ transgene develop a severe, erosive arthritis. Characterization of the cytokine cascade and cellular components. $J$ Immunol 159: 2867-2876.

Chernajovsky Y, Adams G, Triantaphyllopoulos K, Ledda MF, Podhajcer OL 1997. Pathogenic lymphoid cells engineered to express TGF- $\beta 1$ ameliorate disease in a collagen-induced arthritis model. Gene Ther 4: 553-559.

Chernajovsky Y, Adams G, Podhajcer OL, Mueller GM, Robbins PD, Feldmann M 1995a. Inhibition of transfer of collagen-induced arthritis into SCID mice by ex vivo infection of spleen cells with retroviruses expressing soluble tumor necrosis factor receptor. Gene Ther 2: 731-735.

Chernajovsky Y, Annenkov A, Herman C, Triantaphyllopoulos, Gould D, Dreja H, Moyes SP, Croxford JL, Mageed RA, Podhajcer OL, Baker D 1998. Gene therapy for rheumatoid arthritis: theoretical considerations. Drugs Aging 12: 29-41.

Chernajovsky Y, Feldmann M, Maini RN 1995b. Gene therapy of rheumatoid arthritis via cytokine regulation: future perspectives. Br Med Bull 51: 503-516.

Chernajovsky Y, Gould D, Annenkov A, Dreja H, Daly G, Rabinovich GA, Croxford D, Berenstein M, Podhajcer OL 1999. Immunotherapy of autoimmune disease by gene transfer. Biochem Soc Trans 27: 869-873.

Courtenay JS, Dallman MJ, Dayan AD, Martin A, Mosedale B 1980. Immunisation against heterologous type II collagen-induced arthritis in mice. $\mathrm{Na}$ ture 283: 666-668.

Dayer JM 1997. Regulation of IL-1/TNF, their natural inhibitors and other cytokines in chronic inflammation. The Immunologist 5: 192-197.

Elliot M, Maini RN, Feldmann M 1994. Randomised double blind comparison of a chimeric monoclonal 
antibody to tumor necrosis factor alpha (cA2) versus placebo in rheumatoid arthritis. Lancet 344 : 1105-1110.

Evans CH, Robbins PD 1996. Pathways to gene therapy in rheumatoid arthritis. Curr Opin Rheumatol 8: 230234.

Feldmann M, Brennan FM, Maini RN 1996. Rheumatoid Arthritis. Cell 85: 307-310.

Fisher GH, Rosenberg FJ, Straus SE, Dale JK, Middelton LA, Yin AY, Strober W, Lenardo MJ, Puck JM 1995. Dominant interfering Fas gene mutations impair apoptosis in a human autoimmune lymphoproliferative syndrome. Cell 81: 935-946.

Fujisawa K, Aono H, Hasunuma T, Yamamoto K, Mita S, Mishioka K 1996. Activation of transcription factor NF-kB in human synovial cells in response to tumor necrosis factor- $\alpha$. Arthritis Rheum 39: $197-$ 203.

Jorgensen C, Gay S 1998. Gene therapy in osteoarticular diseases: where are we? Immunol Today 19: 387391.

Kerr WG, Mulé JJ 1994. Gene therapy: current status and future prospects. J Leuk Biol 56: 210-214.

Kobayashi T, Okamoto K, Kobata T, Hasunuma T, Kato T, Hamada H, Nishioka K 2000. Novel gene therapy for rheumatoid arthritis by FADD gene transfer: induction of apoptosis of rheumatoid synoviocytes but not chondrocytes. Gene Ther 7: 527-533.

Lenardo MJ 1997. The molecular regulation of lymphocyte apoptosis. Sem Immunol 9: 1-5.

Lubberts E, Joosten LAB, van den Bersselaar L, Helsen MM, Bakker AC, van Meurs JBJ, Graham FL, Richards CD, van den Berg WB 1999. Adenoviral vector-mediated overexpression of IL-4 in the knee joint of mice with collagen-induced arthritis prevents cartilage destruction. J Immunol 163: 4546-4556.

Mageed RA, Adams G, Woodrow D, Podhajcer OL, Chernajovsky Y 1998. Prevention of collagen-induced arthritis by gene delivery of soluble p75 TNF receptor. Gene Ther 5: 1584-1592.

Makarov SS, Olsen JC, Johnston WN 1996. Suppression of experimental arthritis by gene transfer of IL1 receptor antagonist cDNA. Proc Natl Acad Sci USA 93: 402-406.

Mauri C, Williams RO, Walmsley M, Feldmann M 1996. Relationship between Th1/Th2 cytokine patterns and the arthritogenic response in collagen-induced arthritis. Eur J Immunol 26: 1511-1518.

McInnes IB, Leung BP, Sturrock RD, Field M, Liew FY 1997. Interleukin-15 mediates T-cell dependent regulation of tumor necrosis factor- $\alpha$ production in rheumatoid arthritis. Nat Med 3: 189-195.

Okamoto K, Asahara H, Kobayashi T, Matsuno H, Hasunuma T, Kobata T, Sumida T, Nishioka T 1998. Induction of apoptosis in rheumatoid synovium by Fas ligand gene transfer. Gene Ther 5: 331-338.

Oligino T, Ghivizzani SC, Wolfe D, Lechman ER, Krisky D, Mi Z, Evans CH, Robbins PD, Glorioso JC 1999. Intra-articular delivery of a herpes simplex virus IL1-Ra gene vector reduces inflammation in a rabbit model of arthritis. Gene Ther 6: 17131720 .
Otani K, Nita I, Macaulay W, Georgescu HI, Robbins PD, Evans CH 1996. Suppression of antigen-induced arthritis by ex vivo gene therapy. J Immunol 156 : 3558-3562.

Perillo NL, Pace KE, Seihamer JJ, Baum LG 1995. Apoptosis of T-cells mediated by galectin-1. Nature 378: 736-739.

Perillo NL, Uittenbogaart CH, Nguyen JT, Baum LG 1997. Galectin-1: an endogenous lectin produced by thymic epithelial cells, induces apoptosis of human thymocytes. $J$ Exp Med 185: 1851-1858.

Quattrocchi E, Walmsley M, Browne K, Williams RO, Marinova-Mutafchieva L, Buurman W, Butler DM, Feldmann M 1999. Paradoxical effects of adenovirus-mediated blockade of TNF activity in murine collagen-induced arthritis. J Immunol 163: 10001009.

Rabinovich GA 1999a. Galectins: an evolutionarily conserved family of animal lectins with multifunctional properties; a trip from the gene to clinical therapy. Cell Death Diff 6: 711-721.

Rabinovich GA, Ariel A, Hershkoviz R, Hirabayashi J, Kasai K, Lider O 1999b. Specific inhibition of Tcell adhesion to extracellular matrix and pro-inflammatory cytokine secretion by human recombinant galectin-1. Immunology 97: 100-106.

Rabinovich GA, Aronso CR, Sotomayor CE, Durand S, Bocco JL, Riera CM 2000a. Molecular mechanisms implicated in galectin-1-induced apoptosis: activation of the AP-1 transcription factor and downregulation of Bcl-2. Cell Death Diff 7(8) (in press).

Rabinovich GA, Castagna LF, Landa C, Riera CM, Sotomayor CE 1996. Regulated expression of a 16$\mathrm{kd}$ galectin-like protein in activated rat macrophages. J Leuk Biol 59: 363-370.

Rabinovich GA, Daly G, Dreja H, Tailor H, Riera CM, Hirabayashi J, Chernajovsky Y 1999c. Recombinant galectin-1 and its genetic delivery suppress collageninduced arthritis via T cell apoptosis. J Exp Med 190: 385-397.

Rabinovich GA, Iglesias MM, Modesti NM, Castagna LF, Wolfenstein-Todel C, Riera CM, Sotomayor CE 1998. Activated rat macrophgaes produce a galectin1-like protein that induces apoptosis of T cells: biochemical and functional characterization. J Immunol 160: 4831-4840.

Rabinovich GA, Modesti NM, Castagna LF, Landa CA, Riera CM, Sotomayor CE 1997. Specific inhibition of lymphocyte proliferation and induction of apoptosis by CLL-I, a $\beta$-galactoside-binding lectin. J Biochem 122: 365-373.

Rabinovich GA, Riera CM, Iribarren P 1999d. Granulocyte-macrophage colony-stimulating factor protects dendritic cells from liposome-encapsulated dichloromethylene diphosphonate-induced apoptosis through a Bcl-2-mediated pathway. Eur J Immunol 29: 563-570.

Rabinovich GA, Riera CM, Landa CA, Sotomayor CE 1999e. Galectins: a key intersection between glycobiology and immunology. Braz J Med Biol Res 32: 383-393. 
Rabinovich GA, Sotomayor CE, Riera CM, Bianco ID, Correa SG 2000b. Evidence of a role for galectin-1 in acute inflammation. Eur J Immunol 30: 13311339.

Ruchatz H, Leung BP, Wei X, McInnes IB, Liew FY 1998. Soluble IL-15 receptor a-chain administration prevents collagen-induced arthritis: a role for IL-15 in development of antigen-induced immunopathology. J Immunol 160: 5654-5660.

Santucci EL, Fiourucci S, Cammilleri F, Servillo G, Federici B, Morelli A 2000. Galectin-1 exerts immunomodulatory and protective effects on concanavalin-A-induced hepatitis in mice. Hepatology 31: 399-406.

Singer GG, Carrera AC, Marshak-Rothstein A, Martínez AC, Abbas AK 1994. Apoptosis, Fas and systemic autoimmunity: the MRL-lpr/lpr model. Curr Opin Immunol 6: 913-920.

Song K, Chen Y, Göke R, Wilmen A, Seidel C, Göke A, Hilliard B, Chen Y 2000. Tumor necrosis factorrelated apoptosis-inducing ligand (TRAIL) is an inhibitor of autoimmune inflammation and cell cycle progression. J Exp Med 191: 1095-1103.

Takayanagi H, Juji T, Miyazaki T, Iizuka H, Takahashi T, Isshiki M, Okada M, Tanaka Y, Koshihara Y, Oda H, Kurokawa T, Nakamura K, Tanaka S 1999. Suppression of arthritic bone destruction by adenovirus-mediated csk gene transfer to synoviocytes and osteoclasts. J Clin Inv 104: 137-146.
Taniguchi K, Kohsaka H, Inoue N, Terada Y, Ito H, Hirokawa K, Miyasaka N 1999. Induction of the p16 INK4a senescence gene as a new therapeutic strategy for the treament of rheumatoid arthritis. Nat Med 5: 760-767.

Tomita T, Takeuchi E, Tomita N, Morishita R, Kaneko M, Yamamoto K, Nakase T, Seki H, Kato K, Kaneda Y, Ochi T 1999. Suppressed severity of collageninduced arthritis by in vivo transfection of nuclear factor $\mathrm{kB}$ decoy oligodeoxynucleotides as a gene therapy. Arthritis Rheum 42: 2532-2542.

Vaishnaw AK, McNally JD, Elkon KB 1997. Apoptosis in the rheumatic diseases. Arthritis Rheum 40: 19171927.

Vespa GN, Lewis LA, Kozak KR, Moran M, Nguyen JT, Baum LG, Miceli MC 1999. Galectin-1 specifically modulates TCR signals to enhance TCR apoptosis but inhibits IL-2 production and proliferation. J Immunol 162: 799-806.

Weatherall DJ 1995. Scope and limitations of gene therapy. Br Med Bull 51: 1-11.

Williams RO, Feldmann M, Maini RN 1992, Anti-tumor necrosis factor ameliorates joint disease in $\mathrm{mu}$ rine collagen-induced arthritis. Proc Natl Acad Sci USA 89: 9784-9788.

Zhang H, Yang Y, Horton YL, Samoilova EB, Judge TA, Turka LA, Wilson JM, Chen Y 1997. Amelioration of collagen-induced arthritis by CD95 (Apo1/Fas)-ligand gene transfer. J Clin Inv 100: 19511957. 